\title{
Green ICT Assessment for Organisations
}

\author{
Albert Hankel ${ }^{1, *}$, Gaston Heimeriks ${ }^{2}$ \\ and Patricia Lago ${ }^{1}$
}

${ }^{1}$ Vrije Universiteit Amsterdam, Department of Computer Science,
De Boelelaan 1018a, 1081 HV Amsterdam, The Netherlands
${ }^{2}$ Utrecht University, Department of Innovation Studies, Copernicus Institute,
Heidelberglaan 2, 3584 CS Utrecht, The Netherlands
${ }^{*}$ Corresponding Author: a.c.hankel@vu.nl

Received 16 February 2017;

Accepted 8 March 2017

\begin{abstract}
This study shows how a maturity model on Green ICT can help organisations become more environmentally sustainable in a structured and efficient manner. For this we have used the SURF Green ICT Maturity Model and facilitated the use of this model in four organisations. These organisations participated in a maturity scan, an evaluation session to discuss the results of the scan and a questionnaire on the use of the model. The results show that the model delivers specific suggestions for improvement both on reducing the environmental footprint of ICT and on using ICT as a green solution for business processes. Individual participants reported an increase in awareness on what Green ICT can do. We also looked at whether organisations were ready to use Green ICT and identified potential bottlenecks for further adoption and it was possible to identify such bottlenecks using the results of the maturity scan.
\end{abstract}

Keywords: Green ICT, ICT for Sustainability, Green IS, Maturity Model, Assessment.

Journal of ICT, Vol. 4_2, 87-110.

doi: $10.13052 /$ jicts2245-800X.421

(c) 2017 River Publishers. All rights reserved. 


\section{Introduction}

In both academic research and industry the environmental impact of ICT is an important topic spanning multiple disciplines. ICT is seen as both a relevant contributor to $\mathrm{CO}_{2}$-emissions due to its increasing carbon footprint [20], and as an enabler for reducing the footprint of other sectors through "smart" systems (e.g. smart buildings, smart grids). According to a report of the Global e-Sustainability Initiative, ICT itself is roughly responsible for $2,3 \%$ of global $\mathrm{CO}_{2}$-emissions, while ICT solutions have the potential to reduce global $\mathrm{CO}_{2}$-emissions by up to $16 \%$ [2].

While Green ICT is often seen as a field focused solely on reducing the environmental impact of ICT itself, we define Green ICT as a combination of activities that minimise the negative impact of ICT on the environment and optimise the positive impact ICT can have. Or, in other words, as any activity that considers the direct, indirect and systemic impact of ICT on the environment [4]. Because the relations between ICT and the environment are numerous and often complex, it is important to be aware of all these effects: any change may have a direct impact on for example resource consumption, it may optimise other processes (indirect impact) and it could have a long-lasting systemic impact on people's behaviour and thus the larger system (organisation, market, society, etcetera). While these effects are widely recognised and can be understood on an abstract or global level, it is often difficult for individuals or organisations to apply them.

In the past decade more and more organisations have realised that their actions have long term effects on the environment and society and are taking responsibility for their actions through several social and environmental initiatives that reduce their impact [19]. Green ICT can contribute significantly and can thus help organisations achieve their sustainability goals. In order to do so, they need to know how ICT can affect their environmental footprint in both negative and positive ways.

For example, we know that ICT can consume large amounts of energy in datacenters and in (mobile) communication networks [11]. It is also important to consider the use of rare materials in ICT equipment production as well as what happens with the equipment at the end of their life cycle, also known as e-waste [3]. On the other hand, ICT solutions can reduce the need to travel, dematerialise paper use and material use, and optimise business processes as

a whole. When organisations consider Green ICT, they often focus only on the first part, to reduce the environmental impact of ICT. The second part, using ICT as a solution is much less common. 
In the Dutch Higher Education sector, 91\% of the ICT managers consider Green ICT an important factor to help make their organisation more sustainable [13]. Yet, they recognise that there is a lack of knowledge and expertise to make full use of Green ICT. In fact, they asked SURF, the collaborative ICT organisation for Dutch education and research, to help them give:

- a more complete insight into Green ICT and inspiration for improvement;

- knowledge about how well they are doing (compared to others);

- a shared language for knowledge exchange between organisations;

- the ICT department a way to show higher management how they contribute towards larger sustainability goals.

This is why SURF developed the SURF Green ICT Maturity Model (SGIMM) [14], which we describe in Section 3.

For this study we followed four organisations that used the SGIMM to see whether it does in practice what it is designed for. We also wanted to know if the model can help identify issues related to the state of the adoption of Green ICT solutions. We therefore have two research questions:

1. Does the SGIMM deliver in practice what it is designed for and does it address the needs expressed by the ICT managers above?

2. Does the use of the SGIMM identify potential bottlenecks for further adoption of Green ICT?

\section{Related Work}

To put our work into context, we looked at two topics. The first regards other maturity models: which have been published, what are their scopes (with regards to negative and positive impact), and how are they being used. The second is on the adoption of Green ICT: what happens when organisations use such maturity models and what is their general attitude towards sustainability and Green ICT.

\subsection{On Green ICT Maturity Models}

In order to facilitate and promote the use of Green ICT, frameworks and models have been published both in academic and practitioner literature. We also identified general-purpose impact assessment tools that can be applied to ICT, such as life cycle analysis or green house gases audits (see Ecofys et al. [8] for an overview of general tools applied to ICT). Here we focus on those publications that target Green ICT specifically. 
Most of the Green ICT models and tools focus on energy efficiency and reducing the negative impacts of ICT, such as those developed by the Green Grid and the OpenDCME model. While these are mostly focused on data centres, others such as those developed by Gartner [10] and Molla et al. [18] do capture the entirety of ICT. However, they are often limited to the direct impacts in scope or are very abstract. A few tools have been developed to include the positive impacts of ICT, such as those by UK HM Government [12], deMonsabert et al. [6] and Donnellan et al. [7]. Still they mostly focus on the negative impacts as well. From a system perspective (or the total global footprint of society) this seems strange since the negative impacts are responsible for $2 \%$ of that footprint, while the positive impacts have the potential to reduce the global footprint by $16 \%$ [2]. Therefore we argue that models should include both to fully understand the contribution ICT can have.

A few models and frameworks exist that help apply Green ICT principles to business processes in an organisation. For example, the framework in [7] contains the capability building block "ICT-enabled business processes". They found that involving the ICT department as well as 'business' departments raises awareness on both sides of the potential of Green ICT. However, the framework offers little practical guidelines to apply Green ICT to business processes. In general, the impression we gather from other work - and this is also what we experience - is that it is difficult to apply Green ICT outside the datacenter.

From the perspective of practical usability, the published models vary in how abstract they are, their scope and ease of use. Some are very general, simply declaring areas that should be looked at, while others give detailed information on how to improve an element. By looking at the meta-level, it can be seen that most of them have a very similar structure. Most of them have a general idea of what should be included in Green ICT (albeit different from other models), and use a two-tier system (categories in which several components are grouped together). Some of the models include extra aspects such as maturity levels that help give direction for improvement. Such a general structure could indicate a future standard structure for assessing, evaluating and improving the use of green ICT. If many organisations use the same model or at least the same structure in their models, this could pave the way for standardisation and eventually benchmarking.

As far as we can derive from research literature and practice, there is a lack of publications on assessing the quality of the tools, if and how they are being used and whether they achieve their intended effects. Similarly, there has not been a lot of research on what capabilities companies need in order 
to green their ICT and how to measure these capabilities [19]. While such questions might be trivial for other assessment topics, this is not the case for the environmental impact of ICT. Environmental sustainability is typically multidimensional and prone to local optimisations and it is therefore complex to assess progress.

\subsection{On Green ICT Adoption}

Following our definition of Green ICT, a proper use of Green ICT should affect many if not all business processes and activities in an organisation. This means that it has a large impact on most of the staff, requiring them to have the right attitude and skills to use Green ICT. Adoption of Green ICT is therefore not a trivial problem just contained to the technical domain, but a complex one that affects policies and behaviours beyond the ICT staff.

In [17] Molla differentiates between the intention to adopt Green ICT and the actual adoption. The first steps in an organisation are usually taken by a few individuals that were motivated to do so and had enough power to initiate such a change. Even if successful, they often find it difficult to scale up their activities. Molla [17] identified three types of drivers for Green ICT: economic, regulatory and ethical drivers. ICT is consuming large amounts of energy so energy efficiency gains can lead to significant cost reductions in operating ICT. Governments can require ICT within organisations to become compliant with environmental standards. Directive 2012/19/EU of the European Parliament and the European Council on waste electrical and electronic equipment (WEEE) [9] set recycling targets for all types of electrical goods. The government of the Netherlands has signed agreements with many sectors (amongst which the Higher Education sector [1]) to increase energy efficiency every year by $2 \%$. Finally, ethical drivers refer to the pursuit of socially responsible business practices and good corporate citizenship.

Even if an organisation has the intention to adopt Green ICT, this does not necessarily mean that it has the capability to do so. Molla and Cooper [19] argue that there are at least five important properties that they together call the critical capability "G-readiness". These five properties are: attitude, policy, practice, technology and governance. Attitude refers to the extent to which leaders and professionals are aware of and interested in environmental concerns; policy refers to whether there are top-down strategies or other policy documents that push people in the right direction; practice refers to whether the knowledge and skills are present to carry out Green ICT actions; technology refers to the presence of a technological infrastructure that allows 
for environmental friendly actions; and governance refers to the presence of a proper management infrastructure detailing clear roles, responsibilities and relationships [19].

In 2013 we did a survey [13] amongst managers and professionals in the Higher Education sector in the Netherlands that relates to the concept of G-readiness. $91 \%$ of the survey participants stated that they think sustainability is an important topic. In contrast, only 59\% of them believed their own organisation considered it important. The survey respondents recognised a lack of action which was attributed to a shortage on time, a lack of money, a lack of expertise, no priority or split budgets. Each of these can be connected to one or more of the five properties that Molla and Cooper defined as part of G-readiness [19].

It would be interesting to see whether using a maturity model in practice will not only identify areas of improvement that directly affect the environmental footprint, but also identify potential bottlenecks in an organisation to actually adopt Green ICT.

\section{SURF Green ICT Maturity Model (SGIMM)}

SURF, the Dutch higher education and research partnership for ICT, decided to develop a maturity model on Green ICT after interviewing a number of Dutch higher education and research institutions. In these interviews the institutions expressed a clear need for some way to know how well they are doing in terms of Green ICT. SURF wanted to develop a maturity model based on expert views and opinions and validate this through a survey spread amongst practitioners. The SGIMM was developed by SURF in collaboration with the Vrije Universiteit Amsterdam and a number of Green ICT experts, both from the Dutch higher education and research community as well as outside it. Responsibility for ICT in organisations part of this community is typically delegated to an ICT department. The SGIMM was therefore designed from the ICT department's perspective. Even though the SGIMM is developed for higher education, it can be applied by other organisations as it covers topics that are equally relevant for any organisation. More information on the model can be found in [14]. At this website it is also available for download and it can be used freely under a creative commons license.

The notion of maturity model is based on the Capability Maturity Model [21], a framework with five maturity levels for quality and process improvements. The five levels are (1) initial, (2) repeatable, (3) defined, (4) managed and (5) optimising. At the lowest level, the initial level, the organisation does 
not provide a stable environment for the activity. At this level the process is ad hoc. However, at the highest level, which is the optimising level, the entire organisation is focused on continuous process improvement [21].

The SGIMM conceptually consists of four domains covering negative and positive impacts and aspects of ICT. Each domain consists of attributes that have a definition, factors involved and descriptions of each of the five maturity levels. Three domains and attributes are generally applicable to any organisation, being: 'Green ICT in the Organisation', 'Greening of ICT' and 'Greening of Operations with ICT'. The fourth domain is sector-specific and covers 'Greening of primary processes with ICT'. For instance, for the higher education sector, the primary processes would relate to education and research. The first three domains and attributes are summarised in Table 1.

The SGIMM is designed to give organisations insights into the maturity of Green ICT of the organisation. It is set-up as a self-assessment and enables organisations to have an internal dialogue, to gain agreement on the status quo and to define actions for improvement. By letting several individuals within an organisation score the attributes and discussing theses scores with the participants (average, minimum, maximum scores, etc.), an organisation can identify weak and strong Green ICT aspects.

The relevancy and completeness of the SGIMM was evaluated in a survey amongst Dutch practitioners by Hankel et al. [15]. The survey allowed us to

Table 1 Overview of the first three domains and related attributes of the SGIMM

\begin{tabular}{|c|c|c|}
\hline $\begin{array}{l}\text { Green ICT in the } \\
\text { Organisation }\end{array}$ & Greening of ICT & $\begin{array}{l}\text { Greening of } \\
\text { Operations with ICT }\end{array}$ \\
\hline Green ICT Strategy & Housing & $\begin{array}{l}\text { Travel reductions } \\
\text { with ICT }\end{array}$ \\
\hline Governance of ICT & Computing & Area reductions with \\
\hline Services & Infrastructure & ICT \\
\hline Green ICT & Network & Energy reductions \\
\hline Procurement & Infrastructure & with ICT \\
\hline E-waste Policy & $\begin{array}{l}\text { Storage } \\
\text { Infrastructure }\end{array}$ & $\begin{array}{l}\text { Paper reductions with } \\
\text { ICT }\end{array}$ \\
\hline $\begin{array}{l}\text { Green ICT in } \\
\text { Information } \\
\text { Management and } \\
\text { Architecture }\end{array}$ & $\begin{array}{l}\text { End user ICT } \\
\text { equipment }\end{array}$ & $\begin{array}{l}\text { Feedback and } \\
\text { Decision support }\end{array}$ \\
\hline $\begin{array}{l}\text { Community } \\
\text { Collaboration } \\
\text { Green ICT Supply } \\
\text { Chain Management }\end{array}$ & $\begin{array}{l}\text { Software and ICT } \\
\text { services }\end{array}$ & \\
\hline
\end{tabular}


assess the quality of the maturity model and to improve it if necessary. For this study we used the version that was released after these adjustments.

\section{Method of Field Study}

The maturity model was designed to help organisations improve on the use of Green ICT within the organisation. The assumption is that assessing the level of maturity of Green ICT increases awareness and motivation to improve across the full spectrum: from reducing the negative impact of ICT to using ICT as an environmental friendly enabler in other processes. At this point at least, it is impossible to test this theory, as this requires large-scale use of the model and access to organisations using the model versus those not using it. However we do want to see what the effect of using the model is in a qualitative manner.

In order to address our research questions, we carried out a field study where four organisations used the maturity model. The purpose of this study was to see how the SGIMM is used in practice. We facilitated the process of carrying out a maturity scan and collected data for our study while doing so. In addition to the normal process we added a questionnaire to gather individual responses to the use of the model.

\subsection{Data Collection}

The organisations that participated were all facilitated in the same manner. The approach is based on guidelines for a self-scan that are provided in the instructions that come with the maturity model. The following steps were taken (see also Figure 1):

1. The primary contact at the participating organisation was the Assessment Manager (AM), for example the CIO or an ICT manager with sustainability in his or her portfolio. It is important that the AM has the influence and the ability to make sure that the maturity scan is properly done and that follow-up actions are implemented.

2. The AM composed an assessment team. This is a group of people that represents the organisation and were tasked to fill out the maturity model. Their scores are used to get an average maturity score for each attribute. After obtaining the averages, they are discussed during an evaluation session at which also a number of possible actions for improvement are defined. To obtain good results, the right combination of team members is crucial. 
3. The AM explained the purpose of the model and the assessment process to the team (with or without our presence) and sent the SGIMM spreadsheet to all the participants afterwards.

4. All participants individually filled out the spreadsheet and scored all the attributes. When everyone has sent their scores back to the AM, we facilitated the AM by analysing the results and creating a summary.

5. The summary of maturity scores and how it relates to the individual scores are discussed in an evaluation session with the assessment team. We facilitated this by presenting the results and asking questions to promote discussion amongst the team members. Based on this discussion, actions for improvement are defined. We created a report on the results of this evaluation session and shared it with the AM.

6. After the session the participants were asked to fill out a questionnaire on their experience with using the maturity model. As mentioned, the AM was provided with a summary of the process that could then be used to create an action plan.

The evaluation session is the key part in the assessment process, and not necessarily the maturity scores that followed from the individual submissions. The SGIMM is set up in such a way that organisations identify areas of improvement rather than objectively assessing the maturity level of said organisation. Nevertheless, the scores do give a good indication of the maturity of the organisation, especially when combined with and supported by the results of the evaluation session.

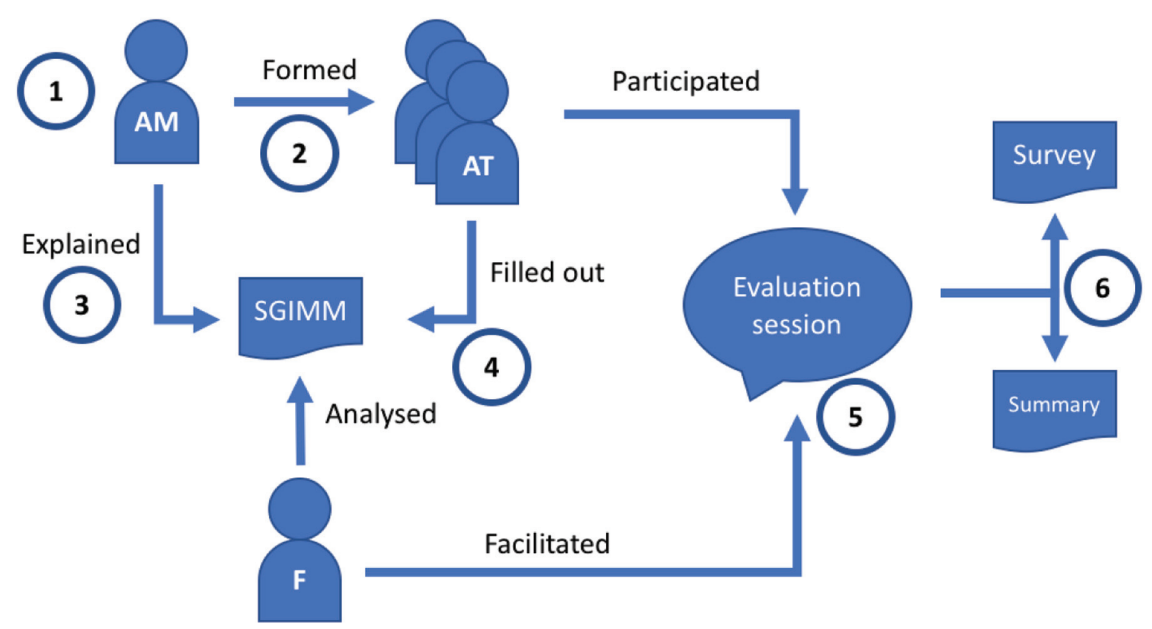

Figure 1 The assessment process in a flow diagram. AM = Assessment Manager; AT = Assessment Team; F = Facilitator. 
The evaluation sessions were facilitated through presenting the analyses of the individual scores combined. Each of the domains was briefly illustrated by showing a radar diagram with the minimum, maximum, and median scores (an example is included in Figure 2). Then the individual scores were shown as in Table 2, in which the scores that deviated by 1 point or more from the average were highlighted. Both strong individual deviations and the general averages were used to stimulate the discussions. The sessions were video-recorded.

The questionnaire after the evaluation session was purposely simple and brief and consisted of the following questions:

- Did you find it useful to fill out the maturity model? Why (not)?

- Did you gain more insight in the possibilities of Green ICT?

- Are you more motivated to apply Green ICT?

- Will you apply more Green ICT in your daily routines?

- Do you have any feedback on the maturity model?

\subsection{Method of Analysis}

In this study we used the results of the maturity scan, the video recording and the questionnaire in our qualitative analysis of the four participating organisations. The direct results of this field study are mostly focused on identifying what can be improved and possibly how they can be improved. Going through the collected data we can find indicators for other aspects as well. This will yield a qualitative description of the state of adoption and identify possible bottlenecks for these organisations.

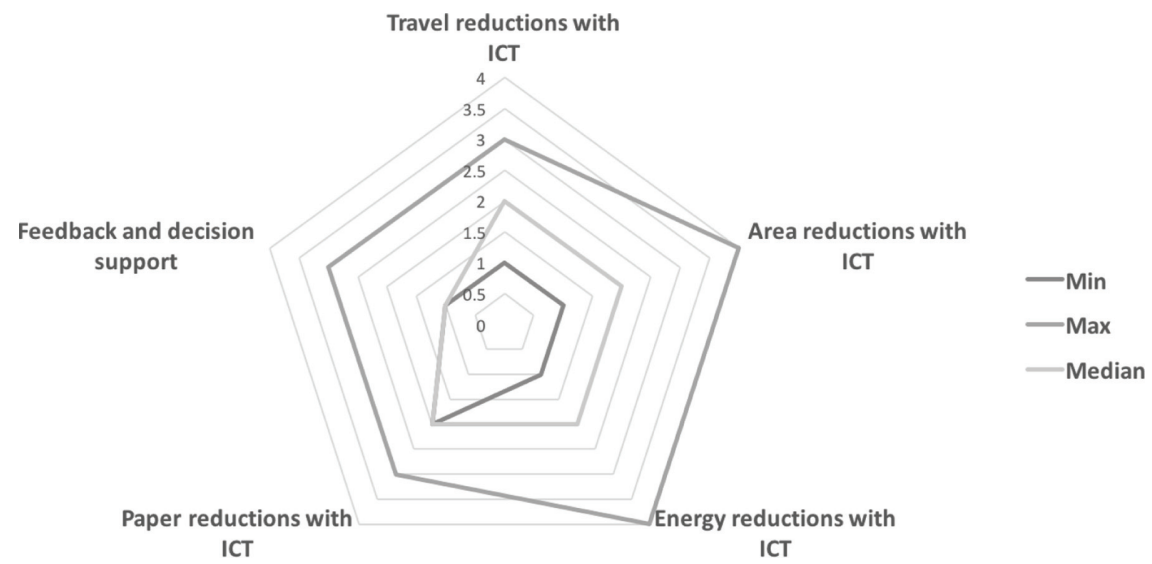

Figure 2 Example of a radar diagram with minimum, maximum and median scores. These scores are not based on a real organisation. 
Table 2 Example of scores with 9 participants. The deviations of 1 point or more from the average are highlighted

\begin{tabular}{|c|c|c|c|c|c|c|c|c|c|c|}
\hline $\begin{array}{l}\text { Greening of Operations } \\
\text { with ICT }\end{array}$ & A & $\mathrm{B}$ & $\mathrm{C}$ & $\mathrm{D}$ & $\mathrm{E}$ & $\mathrm{F}$ & $\mathrm{G}$ & $\mathrm{H}$ & I & Avg \\
\hline $\begin{array}{l}\text { Travel reductions } \\
\text { with ICT }\end{array}$ & 2 & 3 & 2 & 1 & 3 & 2 & 3 & 3 & 2 & 2,3 \\
\hline Area reductions with ICT & 2 & 2 & 1 & 2 & 3 & 3 & 4 & 2 & 2 & 2,3 \\
\hline $\begin{array}{l}\text { Energy reductions } \\
\text { with ICT }\end{array}$ & 1 & 2 & 2 & 3 & 2 & 1 & 4 & 2 & 1 & 2 \\
\hline $\begin{array}{l}\text { Paper reductions } \\
\text { with ICT }\end{array}$ & 2 & 2 & 3 & 3 & 3 & 2 & 3 & 2 & 2 & 2,4 \\
\hline $\begin{array}{l}\text { Feedback and decision } \\
\text { support }\end{array}$ & 1 & 3 & 2 & 1 & 2 & 1 & 3 & 1 & 1 & 1,7 \\
\hline
\end{tabular}

For each of organisations we have collected evidence for the properties of the G-readiness model - attitude, policy, practice, technology and governance [19]. From the descriptions of Molla [19] we adapted checks for each of these properties:

- Attitude - Leaders and professionals, both in ICT and in business, are aware of and interested in the role of ICT in resolving environmental problems.

- Policy - Green ICT and sustainability policies are developed throughout the organisation and permeate the value chain.

- Practice - The organisation has implemented the policies and takes actions to reduce their carbon footprint through the use of ICT.

- Technology - A green (business) infrastructure is present and updated according to the latest green (ICT) standards.

- Governance - An organisation has clearly defined roles and responsibilities for Green ICT activities, administrates them properly, measures their impact and has allocated resources for them.

We have used these checks to see whether the use of the SGIMM gives any indications on these readiness issues. These can then be used to identify possible bottlenecks for the further implementation of Green ICT.

\section{Results}

Four organisations participated in this study. These organisations are all from the Dutch Higher Education sector representing universities and universities of applied sciences. Each has a staff of 3000-5000 employees (including academics) and 20000-40000 students. ICT is a part of normal business 
operations in administrative processes, management systems and as part of office equipment. In addition ICT is used in primary processes for education and research so there is a significant presence of ICT equipment and services and therefore a high potential for influencing the environmental footprint.

\subsection{Results from the Maturity Scan and Questionnaire}

Each organisation had an assessment team of 4-10 members who all filled out the maturity scan individually. Most of the team members were from the ICT department and 1 or 2 were from other departments such as Facilities or other faculty staff. The averages for each organisation on each attribute are shown in Table 3.

In the domain 'Green ICT in the Organisation' we found that for all organisations a Green ICT Strategy document did not exist. Sometimes there was a short position paper on sustainability from an ICT perspective that connected to the general sustainability policies but those were not well known. Good governance of ICT services was common practice for the participating organisations, even without environmental considerations. For other policies usually there were some guidelines that were applied by people motivated to do so, but these were not broadly supported and communicated.

Common practices amongst the participants in the second domain were virtualisation of server hardware, free cooling in data centers (where possible), applying sleep mode in equipment powered over ethernet (e.g. IP telephones), hot-cold-frozen data storage, pc power management and centralising equipment such as printers (shared instead of private use). The organisations found it difficult to balance reliability and availability (redundancy) with energy efficiency, which was reflected in not so green solutions for key elements in the ICT infrastructure such as network equipment. Monitoring on green KPIs was not very common as of yet.

The scores in the third domain 'Greening of operations with ICT' showed more variation between the organisations. One organisation focused more on support for video conference solutions and teleworking, the other offered flexible office space and a third had banned all paper work as much as possible. For most organisations the financial department was having difficulties to transform to paperless. In terms of using ICT to reduce other energy consumption, this seemed quite difficult for all participants because there is not a strong connection between those responsible for ICT and those responsible for building and facility management.

The final domain felt as undiscovered territory for all organisations. Sometimes there is ad hoc collaboration between researchers, teachers or students 
Table 3 Overview of average scores at each of the participating organisations. Minimum score is 1 , maximum is 5

\begin{tabular}{|c|c|c|c|c|}
\hline & A & B & $\mathrm{C}$ & $\mathrm{D}$ \\
\hline \multicolumn{5}{|l|}{ Green ICT in the organisation } \\
\hline Green ICT Strategy & 1,8 & 1,8 & 1,6 & 1,2 \\
\hline Governance of ICT services & 2,6 & 3,8 & 2,6 & 2,8 \\
\hline Green ICT Procurement & 2,1 & 2,6 & 2,1 & 1,8 \\
\hline E-waste Policy & 2,2 & 3,2 & 2,3 & 1,4 \\
\hline Green ICT in Information & 1,7 & 2,0 & 1,4 & 1,4 \\
\hline \multicolumn{5}{|l|}{ Management and Architecture } \\
\hline Community collaboration & 2,3 & 3,0 & 1,8 & 1,6 \\
\hline Green ICT Supply Chain & 2,0 & 2,6 & 1,8 & 1,6 \\
\hline \multicolumn{5}{|l|}{ Management } \\
\hline \multicolumn{5}{|l|}{ Greening of ICT } \\
\hline Housing & 2,0 & 2,2 & 1,8 & 1,6 \\
\hline Computing infrastructure & 1,9 & 2,2 & 1,8 & 1,6 \\
\hline Network infrastructure & 1,6 & 2,2 & 1,6 & 1,3 \\
\hline Storage infrastructure & 2,0 & 2,0 & 1,6 & 1,3 \\
\hline End user ICT equipment & 2,4 & 2,6 & 1,8 & 1,4 \\
\hline Software and ICT services & 1,6 & 1,6 & 1,4 & 1,2 \\
\hline \multicolumn{5}{|l|}{$\begin{array}{l}\text { Greening of Operations } \\
\text { with ICT }\end{array}$} \\
\hline Travel reductions with ICT & 3,0 & 3,0 & 2,3 & 1,8 \\
\hline Area reductions with ICT & 2,7 & 2,6 & 2,3 & 2,4 \\
\hline Energy reductions with ICT & 1,8 & 2,0 & 2,0 & 1,4 \\
\hline Paper reductions with ICT & 2,9 & 2,8 & 2,4 & 2,2 \\
\hline Feedback and decision support & 1,4 & 2,0 & 1,7 & 1,2 \\
\hline \multicolumn{5}{|l|}{$\begin{array}{l}\text { Greening of Primary Processes } \\
\text { with ICT }\end{array}$} \\
\hline Education & 1,5 & 2,0 & 1,9 & 1,6 \\
\hline Education support & 1,6 & 2,0 & 1,7 & 1,6 \\
\hline Research & 1,7 & 1,8 & 1,4 & 1,2 \\
\hline Research support & 1,7 & 1,8 & 1,8 & 1,2 \\
\hline Valorisation & 1,6 & 1,6 & 1,2 & 1,2 \\
\hline Information access & 1,6 & 2,0 & 2,2 & 1,5 \\
\hline
\end{tabular}

and the ICT department but this was rare on the theme of sustainability. All organisations recognised the potential of such a collaboration, especially with those working in fields closely related to the theme, and expressed the intention to explore the possibilities.

The results for the questionnaire are summarised over all participating organisations as they did not show any significant differences between the organisations. 93\% of all individual participants found it useful to use the maturity model. In their comments they commonly wrote that it helped their 
awareness and that it gave insights in where their organisation stood. This was also reflected in their answers to further questions where again $93 \%$ had learned about new possibilities in using Green ICT, 73\% was inspired to promote more Green ICT activity and $67 \%$ was planning to apply Green ICT

principles in their daily work. The feedback on the maturity model consisted of detailed comments that were used to improve the model and general comments that were on the whole positive. Some found it difficult to fill out or said that they needed the evaluation session to fully understand the model.

\subsection{Readiness to Adopt Green ICT}

Besides the direct results of the maturity scan, we also looked at whether organisations were ready to adopt Green ICT or that the use of the maturity model would identify potential bottlenecks for further adoption. What follows is a summary of our observations for each organisation along the lines of attitude, policy, practice, technology and governance.

In organisation A sustainability was an important topic in general policies. For the ICT department this meant that there was room to take sustainable action in terms of budget and other resources, but there was not a strong demand from the board as the strategy was focused on making buildings more energy efficient. The role of ICT in becoming more sustainable was unknown and if any, rather focused on reducing the energy consumption of ICT itself. The effect of this was that the general attitude towards sustain-ability amongst ICT managers and professionals was positive, but that it did not have priority. Often becoming more green was a side-effect of normal business practices. Also, part of the ICT professionals feared that sustain-ability actions would affect their principle priorities such as the reliability of ICT. While a general Green ICT strategy was present, there were little to no policy guidelines on topics such as procurement or e-waste. Because of this all, whether Green ICT actions were taken was strongly dependent on motivated individuals. In addition, there was not much communication between these individuals and the rest of the ICT department on this topic; the same goes for the ICT department and the rest of the organisation. So the possibilities of Green ICT remained unknown. This was also reflected in the governance where sustainability within the ICT department was delegated to these individuals instead of making it a shared responsibility of the entire deparment. Finally, the technical infrastructure could become a bottleneck in the future if steps were taken to let energy consumption match the demand on the infrastructure. Now the infrastructure is designed to 'always on' principles because continuity and reliability are the highest priorities. 
At organisation B sustainability was an important topic in the general strategy. This was felt throughout the organisation and also at the ICT department. There were no specific Green ICT policies however, usually ICT connects to general policies; for procurement for example. There was a wish to develop such policies though. At organisation B a lot of Green ICT activities were being put to practice, but they struggled with promoting new possibilities to users throughout the organisation. Green ICT successes were not visible outside the ICT department. Even though the policies side was lacking, in practice sustainability was almost always considered in projects and activities. In terms of governance, roles and responsibilities were defined and resources were available. The links with other departments outside of ICT could be stronger, but there were connections with facilities and the general sustainability staff. The technical infrastructure was efficient and potentially adaptable to demand. In general in both technical aspects as well as user adoption the possibilities to grow and use Green ICT to become more sustainable were there but the next steps have not been taken yet.

Organisation $\mathrm{C}$ was more formal in their approach to the topic. There was not a specific push from the board to become more sustainable and this was also reflected in the ICT department; it did not have a high priority. The general attitude towards sustainability was cautious, but positive though. Green ICT activities should not affect other business processes negatively. ICT was not fully centralised, which meant that the governance of ICT infrastructure and services was also not fully covered. For both governance and policies there were no specific Green ICT documents implemented. In practice, some Green ICT actions have been taken, or some steps towards more efficiency could also be labeled green. Individuals were certainly willing to take such actions, but sometimes lack the empowerment or the resources. Awareness on Green ICT outside the ICT department was not present, and also little communication about the possibilities of Green ICT. Finally, the technical infrastructure did offer possibilities to make use of Green ICT solutions, but as in other organisations, the priorities of the ICT departments were not at saving energy but at keeping the infrastructure available for all users.

Organisation D was just starting with Green ICT so not many Green ICT actions were put in practice yet. There were some general procurement and waste process principles, but no policies were in place. Awareness on the role of ICT in resolving environmental problems inside and outside the ICT department was low. There was no one responsible for Green ICT yet, so no governance on the the topic either. In fact each readiness aspect was lacking. They were certainly aware of this, however, and really saw the use of the SGIMM as their starting point for implementing Green ICT. 
Table 4 Overview of the readiness to adopt Green ICT for all participating organisations

\begin{tabular}{|c|c|c|c|c|}
\hline & $\mathrm{A}$ & B & $\mathrm{C}$ & $\mathrm{D}$ \\
\hline Attitude & $\begin{array}{l}\text { positive } \\
\text { attitude but } \\
\text { not high } \\
\text { priority in } \\
\text { ICT } \\
\text { department }\end{array}$ & $\begin{array}{l}\text { positive } \\
\text { attitude, both } \\
\text { from general } \\
\text { management } \\
\text { as in ICT } \\
\text { department }\end{array}$ & $\begin{array}{l}\text { cautious but } \\
\text { positive } \\
\text { attitude; not a } \\
\text { priority }\end{array}$ & $\begin{array}{l}\text { lack of } \\
\text { awareness } \\
\text { throughout }\end{array}$ \\
\hline Policy & $\begin{array}{l}\text { general } \\
\text { strategy } \\
\text { present but } \\
\text { no concrete } \\
\text { guidelines }\end{array}$ & none in place & none in place & none in place \\
\hline Practice & $\begin{array}{l}\text { actions have } \\
\text { been taken } \\
\text { but highly } \\
\text { dependant on } \\
\text { motivated } \\
\text { individuals }\end{array}$ & $\begin{array}{l}\text { many actions } \\
\text { have been } \\
\text { taken; } \\
\text { struggle to } \\
\text { get users to } \\
\text { take } \\
\text { advantage }\end{array}$ & $\begin{array}{l}\text { some actions } \\
\text { have been } \\
\text { taken; mostly } \\
\text { driven by } \\
\text { motivated } \\
\text { individuals }\end{array}$ & just starting \\
\hline Technology & $\begin{array}{l}\text { designed for } \\
\text { energy } \\
\text { efficient } \\
\text { 'always on'; } \\
\text { other } \\
\text { priorities may } \\
\text { prevent } \\
\text { further steps }\end{array}$ & $\begin{array}{l}\text { potential } \\
\text { present but } \\
\text { not fully } \\
\text { taken } \\
\text { advantage of }\end{array}$ & $\begin{array}{l}\text { potential } \\
\text { present but } \\
\text { other } \\
\text { priorities may } \\
\text { collide }\end{array}$ & nothing specific \\
\hline Governance & $\begin{array}{l}\text { delegated to } \\
\text { individuals; } \\
\text { not seen as a } \\
\text { shared } \\
\text { responsibility }\end{array}$ & $\begin{array}{l}\text { roles and } \\
\text { responsibili- } \\
\text { ties defined; } \\
\text { resources } \\
\text { available }\end{array}$ & $\begin{array}{l}\text { nothing } \\
\text { defined }\end{array}$ & nothing defined \\
\hline
\end{tabular}

When framed in the aspects of attitude, policy, practice, technology and governance, the four organisations vary in their readiness to adopt Green ICT. In Table 4 the above observations are summarised.

\section{Discussion}

The goal of the SURF Green ICT Maturity Model is to help organisations learn more about the possibilities of Green ICT in a practical and efficient 
way. It gives an overview of the most important issues and areas that can be addressed with Green ICT. As demonstrated in the results, organisations gain insight in both the ICT-as-a-problem side as well as the ICT-as-a-solution side in their particular situation.

Looking at the most common improvement suggestions (for example: putting a green paragraph in project documents, implementing total-cost-ofownership in procurement, virtualisation of servers, promoting teleworking, using power-over-ethernet solutions, improving asset management and monitoring) a pattern seems to emerge that organisations have started picking the low hanging fruits and are slowly moving beyond these. Some areas are clearly deemed to be too advanced to take on for now, such as green supply chain management and applying green principles in software and ICT services. The concept of a maturity model works well to identify where an organisation stands and how it can improve. The SGIMM also offers many ways to connect the ICT department with other departments and the board to show how ICT can be used to resolve environmental problems. The model can be applied in an improvement cycle and used as a report. Measuring the Green ICT maturity repeatedly in a standard way allows organisations to see whether they grow in maturity.

The questionnaire gave us insight in what the individual attitude of the participants was regarding Green ICT and the maturity model itself. The results of the questionnaire are quite clear: almost everyone found it a useful (and efficient) way to get an overview on where their organisation stands and quickly generate ideas for improvement. Furthermore, they increased their own awareness, learned more about the possibilities of Green ICT (beyond actions in the datacenter and also apply ICT as an environmental solution in business processes), and two third actually planned to apply Green ICT principles in their daily work. Even though this is a field study with limited participants, the general attitude is highly positive and seems a good indication of the positive effects the use of such a maturity model can have.

We did not facilitate a benchmark or a joint session with all participating organisations. Yet, because the use of the model is standardised, comparisons can be made easily; both on scores as well as ideas for improvement. So we envision the possibility to use the maturity model as a benchmark tool to compare multiple organisations. It could be especially effective to identify best practices in this way and stimulate organisations to exchange these amongst themselves.

Based on the experiences with and the results of the four organisations we can therefore conclude that the SGIMM does what it is designed for these organisations: it gives suggestions for improvement on both the problem and 
the solution side of ICT and it can be used to address the needs of the ICT managers. Next to the direct results of the maturity scan, we also looked at whether the SGIMM could identify potential bottlenecks for further adoption of Green ICT.

The issues and solutions that participants talked about in the evaluation sessions were quite similar for the four organisations. In each case there was someone who was giving good examples on how to procure more environmentally friendly or dispose of equipment properly. However, their methods were not formalised in policies and enforced and therefore formalising individual methods into policies was a common suggestion for improvement. Similarly, communicating about what is already there, from policy documents to good practices was also a popular action to follow-up with. Especially in the 'Greening of ICT' domain, reduction possibilities were in place, but not taken advantage of by users. The same goes for ICT facilities such as videoconferencing to reduce traveling. Promotion of and communication about these solutions is a key activity for all participants (to different degrees). Since these are typical signs of bottom-up enthusiasm, the reverse may also be true that the main issue behind the above observations is a lack of top-down support. This was also sometimes mentioned in the discussions, especially related to Green ICT Strategy: with a strong and clear strategy it would become much easier to take the next step.

Looking at the individual organisations we saw that at organisation A the enthusiasm is there but there is hardly any sense of urgency or importance. We suspect that it will be difficult for them to move beyond the individual ad hoc level, even though many actions could be taken in practice. Organisation B was clearly the most mature with good support from the board. There was a lack of policies on Green ICT as well as a lack of awareness outside the ICT department that made the progress feel fragile. In organisation C sustainability was not a priority which made it difficult to get things done. It would make sense for them to focus on their readiness to adopt Green ICT rather than take Green ICT actions. And finally, for organisation D Green ICT was clearly new and they wanted to use the maturity model as a starting point.

As we have seen, the results of the maturity scan can certainly be used to identify potential bottlenecks. This may not be evident from the results directly but combined with another framework such as the G-readiness model by Molla [19] it is possible to highlight problem areas for further adoption of Green ICT. 
For future work, we will consider following the participating organisations over a longer period of time to see if they actually follow-up on the results of their maturity scan. It would be interesting to see whether they would write an action plan and carry out improvement actions. After a year or so, the organisation can then repeat the maturity scan to see where they stand compared to the year before. Such a comparison would give insight in whether the use of the model is actually effective in improving the maturity and therefore the greenness of an organisation. Furthermore, we can also see whether the potential bottlenecks that we identified have become reality.

\section{Conclusion}

The work described in this study focused on making Green ICT more practical for organisations as well as identify potential bottlenecks for the adoption of Green ICT. Often organisations know they need to make their data center more energy efficient by turning up the heat or thinking carefully about how they cool their equipment but they do not look beyond the data center. For Green ICT to be truly effective, organisations need to know how they can both reduce the environmental footprint of their ICT equipment as well as how to use their ICT equipment to help reduce the footprint of their other business activities. The SURF Green ICT Maturity Model is designed to address exact this issue.

We wanted to know whether the SGIMM does in practice what it is designed for. We illustrated this through a field study that followed four organisations which used to maturity model to gain insight in where they stand as well as to get inspired to take action. By using the model not only to get an overall impression of the maturity model Green ICT, but also to discuss the results with participants in an evaluation session, the value of the maturity model was clear to the participants. Both individuals and organisations as a whole, were very positive on the use of the maturity model. It increased awareness, inspired to take action and was insightful. A model such as the SGIMM can be used to benchmark amongst organisations, and become a standard way of measuring and addressing Green ICT.

We also found that the results of a maturity scan can be used to identify potential bottlenecks for the adoption of Green ICT. By combining the SGIMM with the G-readiness model [19] it was possible to see whether organisations were ready in terms of attitude, policy, practice, technology and governance. 


\section{References}

[1] Rijksoverheid (2008). VROM, WWI, VSNU en Hbo-Raad Maken Afspraken over Duurzaamheid in het Hoger Onderwijs, Available at: http://www.rijksoverheid.nl/nieuws/2008/12/03/vrom-wwivsnu-en-hbo raad-maken-afspraken-over-duurzaamheid-inhet-hoger- onderwijs.html

[2] Global e-Sustainability Initiative (GeSI) (2015). \#SMARTer2030, ICT Solutions for 21 st Century Challenges. Brussels: Global e-Sustainability Initiative (GeSI).

[3] Ramesh Babu, B., Parande, A. K., and Basha, C. A. (2007). Electrical and electronic waste: a global environmental problem. Waste Manag. Res. 25, 307-318.

[4] Berkhout, F., and Hertin, J. (2001). Impacts of Information and Communication Technologies on Environmental Sustainability: Speculations and Evidence. Report to the OECD, Brighton: University of Sussex.

[5] Curry E., Conway G., Donnellan B., Sheridan C., and Ellis K. (2013). "Measuring energy efficiency practices in mature data center: a maturity model approach," In Computer and Information Sciences III, E. Gelenbe, and R. Lent (London: Springer), 51-61.

[6] deMonsabert, S., Odeh, K., and Meszaros, J. (2012). "Sustainabits: A framework and rating system for sustainable it," in Proceedings of the 2012 International Green Computing Conference (IGCC), San Jose, CA, 1-9.

[7] Donnellan, B., Sheridan, C., and Curry, E. (2011). A capability maturity framework for sustainable information and communication technology. IT Prof. 13, 33-40.

[8] Ecofys, Quantis, and BIO Intelligence Service (2013). Ict Footprint: Pilot Testing on Methodologies for Energy Consumption and Carbon Footprint of the Ict-Sector. Brussels: European Commission.

[9] European Union (2012). EU. Waste Electrical and Electronic Equipment Directive. Available at: http://eur-lex.europa.eu/LexUriServ/ LexUriServ.do?uri=OJ:L:2012:197:0038:0071:EN:PDF

[10] Gartner (2013). Introducing the Gartner Green and Sustainable it Infrastructure and Operations Maturity Model. Stamford, CT: Gartner.

[11] Gelenbe, E., and Caseau, Y. (2015). The Impact of Information Technology on Energy Consumption and Carbon Emissions. San Jose, CA: Ubiquity.

[12] UK HM Government (2013). Green Ict Maturity Model, London: UK HM Government. 
[13] Hankel, A. (2013). National collaboration on green ict in the dutch higher education: lessons learned. On Inform. Commun. Technol. 203.

[14] Hankel, A. (2015). Surf Green ICT Maturity Model. Available at: http://www.surf.nl/sgimm

[15] Hankel, A., Oud, L., Saan, M., Lago, P., et al. (2014). "A maturity model for green ICT: the case of the surf green ICT maturity model," in Proceedings of the 28th EnviroInfo 2014 Conference, Oldenburg, 33-40.

[16] Köhler, A., and Erdmann, L. (2004). Expected environmental impacts of pervasive computing. Hum. Ecol. Risk Assess. 10, 831-852.

[17] Molla, A. (2008). "Gitam: a model for the adoption of green it," in Proceedings of the 19th Australasian Conference on Information Systems, Christchurch, 64.

[18] Molla, A., and Cooper, V. (2010). Green it readiness a framework and preliminary proof of concept. Aust. J. Inform. Syst. 16, 140-160.

[19] Molla, A., Cooper, V., and Pittayachawan, S. (2009). "It and ecosustainability: developing and validating a green it readiness model," in Proceedings of the 30th International Conference on Information Systems, Phoenix, AZ.

[20] Murugesan, S. (2008). Harnessing green IT: principles and practices. IT Prof. 10, 24-33.

[21] Paulk, M. C., Curtis, B., Chrissis, M. B., and Weber, C. V. (1993). Capability maturity model, version 1.1. Software IEEE, 10, 18-27.

\section{Biographies}

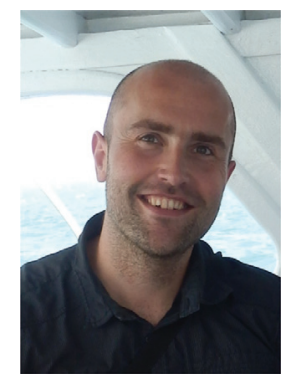

A. Hankel is product manager and project manager at SURFnet, the Dutch National Research and Education Network, and worked on sustainability projects since 2009. These projects range from auditing the energy use of the SURFnet network and office; publishing white papers and guides on Green ICT; to stimulating Green ICT communities. In 2012 he joined the GÉANT 
Green Team where he collaborates on Green ICT projects with other NRENs in Europe. Albert started working at SURFnet in 2007 after obtaining his Master of Science degree in Artificial Intelligence at the University of Groningen. $\mathrm{He}$ is currently pursuing a Ph.D. at the VU University Amsterdam on Green ICT and how organisations can make use of Green ICT. In his research he developed the SURF Green ICT Maturity Model which is designed in such a way that organisations can efficiently assess their current use of Green ICT and generate suggestions for improvements.

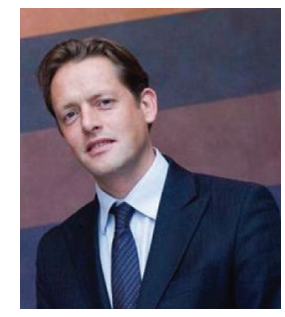

G. Heimeriks is Assistant Professor at the Department of Innovation Studies, Copernicus Institute, Utrecht University. An interdisciplinary academic by choice, Heimeriks' efforts focus on understanding the complex dynamics arising from the co-evolution of knowledge, economy and societal institutions. He has many years of experience as a researcher and policy adviser on science, technology and innovation. A common theme in his work is the understanding and governance of scientific, technological and social change in the knowledge society. He has published on topics such as the evolution of knowledge, foresight, ICT methodologies, indicators, new modes of knowledge production and research policy. Gaston Heimeriks has a background in biochemistry (M.Sc.) and in science and technology studies (M.A.) He previously worked as a researcher at the University of Amsterdam and the Dutch Royal Academy of Sciences on European projects dealing with the influence of ICT on the development of the science-technology-economy system. His research resulted in a Ph.D. at the University of Amsterdam in 2005. Gaston also worked at the Institute for Prospective Technological Studies (IPTS) in Seville, one of the seven scientific institutes of the European Commission's Joint Research Centre, for the Dutch Advisory Council for Science and Technology Policy (AWT) and as a senior researcher at STePS Twente. 


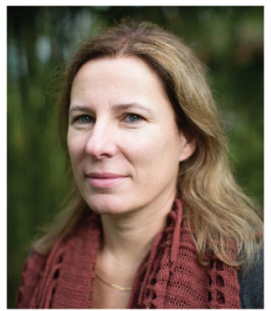

P. Lago is professor at the Vrije Universiteit Amsterdam, the Netherlands, where she leads the Software and Services research group in the Computer Science Department. Her passion in research is to create software engineering knowledge that makes software better, smarter, and more sustainable. Her philosophy is that research should be industrial-relevant and serve the final purpose of being applied in practice. To this end, her research specifically focuses on the 'real' needs of practice by establishing collaboration with partners from both private and public sectors. She has a Ph.D. in Control and Computer Engineering from Politecnico di Torino and a Master in Computer Science from the University of Pisa, both in Italy. She is member of the Steering Committees of IEEE/IFIP ICSA, ECSA and the ICT4S conference series, member of the IFIP 2.10 Working group on Software Architecture, the IFIP 2.14 Working group on Services-based Systems, and the Dutch Knowledge Network on Green Software. She has published in all major conferences and journals of her field. Her research and teaching are about software architecture, software design and modeling, software quality assessment and software sustainability. She is initiator and coordinator of the Computer Science Master Track in Software Engineering and Green IT. She co-founded the Green Lab, a place where researchers, students and companies collaborate to measure the energy footprint of software solutions. More information online at www.cs.vu.nl/patricia and www.s2group.cs.vu.nl. 
